\title{
Serum Insulin-like growth factor-1 levels of healthy adults in southern China
}

\author{
Zhi-hong Liao ${ }^{1)}$, Qi-qi Yin ${ }^{1)}$, Jian-xin $\mathrm{Wan}^{2)}$, Wei $\mathrm{He}^{1)}$, Wen $\mathrm{Ji}^{1)}$, Lu-yao Zhang ${ }^{1)}$ and Yan-bing $\mathrm{Li}^{1)}$ \\ 1) Endocrinology Department, First Affiliated Hospital of Sun Yat-Sen University, Guangzhou, P.R. China \\ 2) Central Laboratory, First Affiliated Hospital of Sun Yat-Sen University, Guangzhou, P.R. China
}

\begin{abstract}
It is to establish the normal range and investigate the distribution characteristics of serum Insulin-like growth factor-1 (IGF-1) for healthy adults in southern China. IGF-1 levels of 515 healthy adults (254 males and 261 females) were measured by automated chemiluminescence immunoassay. The subjects were strictly selected healthy volunteers, aged 20 to 84 years old, with equal five year intervals and without abnormal conditions that impacted IGF-1 levels. The reference ranges were calculated using the smooth centile curves of the LMS method (L: coefficient of skewness, M: median, S: coefficient of variation). IGF-1 declined with aging in adults. There were statistically significant differences for the IGF-1 levels between men and women in some subgroups of age. Gender differences varied depending on the age. Middle-aged females had higher IGF-1 whilst elder females had lower IGF-1. The statistical differences were seen in three subgroups of age between this study and a German cohort that is the reference range for the laboratory test kit. Here, the age- and gender-specific normal range was established for Chinese adults. A Z Score of IGF-1 for an individual could be obtained via the LMSchartmaker application, which standardized IGF-1 research worldwide.
\end{abstract}

Key words: Insulin-like growth factor-1, Reference range, Centile curves, LMS method, Chinese adults

IT is much required to establish the normal reference range of Insulin-like growth factor-1 (IGF-1) in southern China. As we know, IGF-1 is a coral and sensitive index for evaluating the function of growth hormone (GH) -IGF somatotropic axis. IGF-1 level in blood is relatively stable compared to growth hormone $(\mathrm{GH})$. The 2014 acromegaly clinical practice guideline recommended that the measuring of IGF-1 was more important than $\mathrm{GH}$ for screening and following-up [1]. It is recommended to have a normal IGF-1 reference range for a local district because of the racial/ethnical influences on IGF-1 levels $[1,2]$. It is not possible to use a single range of normal values representing the level of IGF-1 in different areas and races. It is also suggested that patients should be followed up for IGF-1 levels with the same kind of detection method in the same laboratory [3].

Italy [4], Germany [5], Thailand [6], Brazil [7],

Submitted Mar. 15, 2016; Accepted Jul. 29, 2016 as EJ16-0144

Released online in J-STAGE as advance publication Aug. 26, 2016

Correspondence to: Yan-bing Li, Endocrinology Department, First Affiliated Hospital of Sun Yat-Sen University, Zhongshan Rd 2, No58, Guangzhou, P.R. China (Zip Code 510080).

E-mail: easd04lyb@126.com

(C)The Japan Endocrine Society
Japan [8] and other countries, have established their local reference ranges of IGF-1 in a certain age group of people using various measurement methods. In this study, the chemiluminescence (IMMULITE 2000, SIEMENS) [5], the most commonly used method in China, was applied to measure the serum IGF-1 values in a group of healthy southern Chinese adults in order to establish the normal reference range. Its distribution characteristics were analyzed. The racial differences of IGF-1 were analyzed by the comparison with the report of MW Elmlinger's group that was adopted for the normal reference of the kit [5]. The Elmlinger's report came from a German cohort which had the comparable ages with our adults. Reference centile curves of IGF-1 was established using the LMS method (L, coefficient of skewness; $\mathrm{M}$, the median; S, coefficient of variation) $[8,9]$.

\section{Materials and Methods}

\section{Subjects}

515 healthy adults (254 men, 261 women) from southern China (aged 20-84) participated in the research. The enrollment criteria included: the Han 
nationality, having lived for over two years in southern China, BMI of $18.5-28 \mathrm{~kg} / \mathrm{m}^{2}$, normal height in-between $\pm 2 \mathrm{SD}$ of Chinese adults, smoking less than 20 cigarettes per day, drinking no more than $75 \mathrm{~g}$ of alcohol per day, no sepsis, no stress reaction, no past respiratory system diseases (upper respiratory tract infection, pneumonia, bronchial asthma, COPD, tuberculosis, bronchiectasis), no cardiovascular system diseases (coronary heart diseases, heart failure, myocardial inflammatory disease), no digestive system diseases (hepatitis, liver cirrhosis, fatty liver), no urinary system diseases (glomerular nephritis, nephritic syndrome, renal failure), no endocrine and metabolic system diseases (diabetes, thyroid dysfunction, serum cholesterol $\geq 6.22 \mathrm{mmol} / \mathrm{L}$, serum triglyceride $\geq 2.26$ $\mathrm{mmol} / \mathrm{L}$, blood uric acid $\geq 480 \mu \mathrm{mol} / \mathrm{L}$ ), no autoimmune diseases (SLE, rheumatoid arthritis, dry syndrome, arthritis, Behcet's disease), no blood system disease (anemia, polycythemia, leukemia, ITP), no malignant tumors (breast/prostate/lung/colorectal cancer etc.), free of fever or cold symptoms within two weeks, no antibiotics within two weeks, not having been admitted into a hospital within one month, without blood transfusion or blood donation within three months, no operation within six months, child-bearing aged women were neither lactating, gestating, or postpartum for more than one year and no HIV, HBV, HCV or syphilis infections. This research had been approved by the Ethical Committee of First Affiliated Hospital of Sun Yat-Sen University and all volunteers signed the informed consent form.

\section{Methods}

Assay

Fasting blood serum was collected and stored at $-80^{\circ} \mathrm{C}$. Centralized chemiluminescence (IMMULITE 2000, SIEMENS) was used to detect serum IGF-1 levels within two months. The kit was calibrated according to the WHO International Reference Reagent for IGF-1 Immunoassays (87/518) [5].

\section{Statistics}

The IGF-1 values showed as normal distribution and were described as Mean, Standard Deviation (SD), Median, 95\%CI and grouped by age and gender. Two independent samples $t$-test was used to compare IGF-1 values of two different genders at the same age subgroup when there was homogeneity of variance, and $t$ '-test was used when there was heterogeneity of variance. Summary $t$-test was used to compare the mean values of IGF-1 with those established by Elmlinger's group. SPSS 20 was used and $P<0.05$ means statistical significance. The centile curves were constructed using the LMS method via LMSchartmaker Pro (version $2.54 \mathrm{http} / / / \mathrm{www} . h e a l t h f o r a l l c h i l d r e n . c o m / ;$ 2011) [9].

\section{Results}

\section{The IGF-1 distribution characteristics of healthy adults in southern China}

In adulthood, IGF-1 values decreased gradually with aging in both males and females. Compared within the same age subgroups, the IGF-1 values of different genders reached significant differences $(p<0.05)$ in the subgroups of 30-34, 35-39, and over 70 years old, females being higher in the two younger subgroups and lower in the subgroup of over 70 (Table 1). However, there was no significant difference for gender if compared in the combined ages. The subgroup of totality and the subgroup of 40-44 had heterogeneity of variance, so $t^{\prime}$-tests were used.

\section{Comparing IGF-1 of this data with Elmlinger's study}

Summary $t$-test was used to compare the two sets of data, our data $v s$ Elmlinger's report [5], sub-grouped at the same age ranges. The IGF-1 levels showed higher than Elmlinger's in four subgroups of ages 21-35 and 66-70 $(p<0.05)$ (Table 2).

\section{Curve fitting of IGF-1 vs age}

The optimal centile curves of Median were constructed as cubic splines by non-linear regression at the equivalent degrees of freedom L(3), M(5) and S(3) using penalised likelihood via LMSchart Pro [9] (Table 3 and Fig. 1).

\section{Discussions}

We know the coral important role for the establishment of standardized IGF1 reference range in China. Standardized analysis and interpretation of IGF1 have emerged as a useful diagnostic tool and an essential follow-up tool for the management of GH deficiency [10] or acromegaly [1]. Study for standard deviation score, also known as Z score, of IGF-1 is lacking in China. This data is very valuable because the healthy volunteers were strictly selected avoiding any conditions, besides age/gender, affecting the IGF-1 levels. 
Table 1 IGF-1 distribution characteristics of healthy adults in southern China ( $\mathrm{ng} / \mathrm{mL})$

\begin{tabular}{|c|c|c|c|c|c|c|c|}
\hline Ages & Gender & Number & Mean & Lower 95\%CI & Upper 95\%CI & SD & Medium \\
\hline \multirow[t]{3}{*}{$20-24$} & Male & 24 & 258.208 & 221.223 & 295.193 & 87.588 & 247.5 \\
\hline & Female & 32 & 253.875 & 226.82 & 280.93 & 75.041 & 245 \\
\hline & & 56 & 255.732 & 234.33 & 277.134 & 79.918 & 231 \\
\hline \multirow{3}{*}{$25-29$} & Male & 32 & 229.844 & 199.948 & 259.74 & 82.921 & 223 \\
\hline & Female & 27 & 244.481 & 215.862 & 273.101 & 72.346 & 248 \\
\hline & & 59 & 236.542 & 216.23 & 256.855 & 77.945 & 215 \\
\hline \multirow[t]{3}{*}{$30-34 *$} & Male & 38 & 191.274 & 176.205 & 206.342 & 45.843 & 185 \\
\hline & Female & 28 & 224.679 & 204.19 & 245.168 & 52.84 & 215 \\
\hline & & 66 & 205.446 & 192.832 & 218.059 & 51.31 & 201.5 \\
\hline \multirow[t]{3}{*}{$35-39 *$} & Male & 20 & 176.7 & 157.081 & 196.319 & 41.92 & 173 \\
\hline & Female & 31 & 212.3 & 190.106 & 234.494 & 60.507 & 219 \\
\hline & & 51 & 198.339 & 182.497 & 214.181 & 56.326 & 188 \\
\hline \multirow[t]{3}{*}{$40-44$} & Male & 34 & 163.256 & 148.934 & 177.577 & 41.046 & 160 \\
\hline & Female & 25 & 168.752 & 139.352 & 198.151 & 71.224 & 142 \\
\hline & & 59 & 165.585 & 151.157 & 180.013 & 55.364 & 153.5 \\
\hline \multirow[t]{3}{*}{$45-49$} & Male & 25 & 152.98 & 134.662 & 171.298 & 44.378 & 157 \\
\hline & Female & 34 & 154.432 & 140.337 & 168.528 & 40.398 & 152 \\
\hline & & 59 & 153.817 & 142.934 & 164.7 & 41.761 & 148 \\
\hline \multirow[t]{3}{*}{$50-54$} & Male & 27 & 146.739 & 125.434 & 168.044 & 53.857 & 137 \\
\hline & Female & 34 & 143.153 & 128.383 & 157.923 & 42.332 & 138.5 \\
\hline & & 61 & 144.74 & 132.603 & 156.877 & 47.39 & 143 \\
\hline \multirow[t]{3}{*}{$55-59$} & Male & 24 & 151.271 & 130.528 & 172.013 & 49.122 & 155.5 \\
\hline & Female & 21 & 138.367 & 122.827 & 153.907 & 34.139 & 138 \\
\hline & & 45 & 145.249 & 132.385 & 158.113 & 42.819 & 140.5 \\
\hline \multirow[t]{3}{*}{$60-64$} & Male & 12 & 146.942 & 116.395 & 177.488 & 48.076 & 141.5 \\
\hline & Female & 7 & 133.071 & 110.37 & 155.773 & 24.547 & 131 \\
\hline & & 19 & 141.832 & 122.191 & 161.473 & 40.75 & 140 \\
\hline \multirow[t]{3}{*}{$65-69$} & Male & 8 & 159.525 & 124.567 & 194.483 & 41.815 & 162 \\
\hline & Female & 10 & 124.57 & 103.343 & 145.797 & 29.673 & 116.5 \\
\hline & & 18 & 140.106 & 120.81 & 159.401 & 38.801 & 135 \\
\hline \multirow[t]{3}{*}{$\geq 70^{*}$} & Male & 10 & 139.2 & 99.126 & 179.274 & 56.019 & 129.5 \\
\hline & Female & 12 & 98.816 & 82.02 & 115.611 & 26.434 & 104 \\
\hline & & 22 & 117.172 & 96.688 & 137.657 & 46.202 & 116.5 \\
\hline
\end{tabular}

“*” means statistical significance when comparing males with females in the same age subgroup.

Table 2 Comparison of this study with Martin W. Elmlinger's normal range of IGF-1 (ng/mL)

\begin{tabular}{|c|c|c|c|c|c|c|c|c|}
\hline \multirow[t]{2}{*}{ Age } & \multicolumn{3}{|c|}{ Martin W. Elmlinger } & \multicolumn{3}{|c|}{ This study } & \multirow{2}{*}{$t$-test } & \multirow{2}{*}{$p$} \\
\hline & $\mathrm{N}$ & Mean & SD & $\mathrm{N}$ & Mean & SD & & \\
\hline $21-25$ & 155 & 199 & 63 & 62 & 242 & 73 & -4.336 & $<0.001^{*}$ \\
\hline $26-30$ & 54 & 194 & 57 & 60 & 229 & 68 & -2.96 & $0.004^{*}$ \\
\hline $31-35$ & 48 & 183 & 52 & 61 & 207 & 56 & -2.292 & $0.024 *$ \\
\hline $36-40$ & 52 & 171 & 48 & 55 & 189 & 57 & -1.762 & 0.081 \\
\hline $41-45$ & 50 & 160 & 45 & 52 & 161 & 52 & -0.104 & 0.918 \\
\hline $46-50$ & 50 & 149 & 44 & 75 & 150 & 43 & -0.126 & 0.9 \\
\hline $51-55$ & 52 & 140 & 42 & 46 & 147 & 46 & -0.787 & 0.433 \\
\hline $56-60$ & 48 & 131 & 40 & 44 & 146 & 44 & -1.713 & 0.09 \\
\hline $61-65$ & 78 & 123 & 37 & 15 & 134 & 35 & -1.063 & 0.291 \\
\hline $66-70$ & 22 & 115 & 35 & 15 & 141 & 40 & -2.094 & $0.044 *$ \\
\hline $71-75$ & 56 & 107 & 34 & 16 & 128 & 48 & -1.978 & 0.052 \\
\hline $76-80$ & 24 & 99 & 33 & 5 & 84 & 29 & 0.941 & 0.355 \\
\hline
\end{tabular}


Table 3 Serum IGF-I reference ranges, and L, M, and S parameters for adults

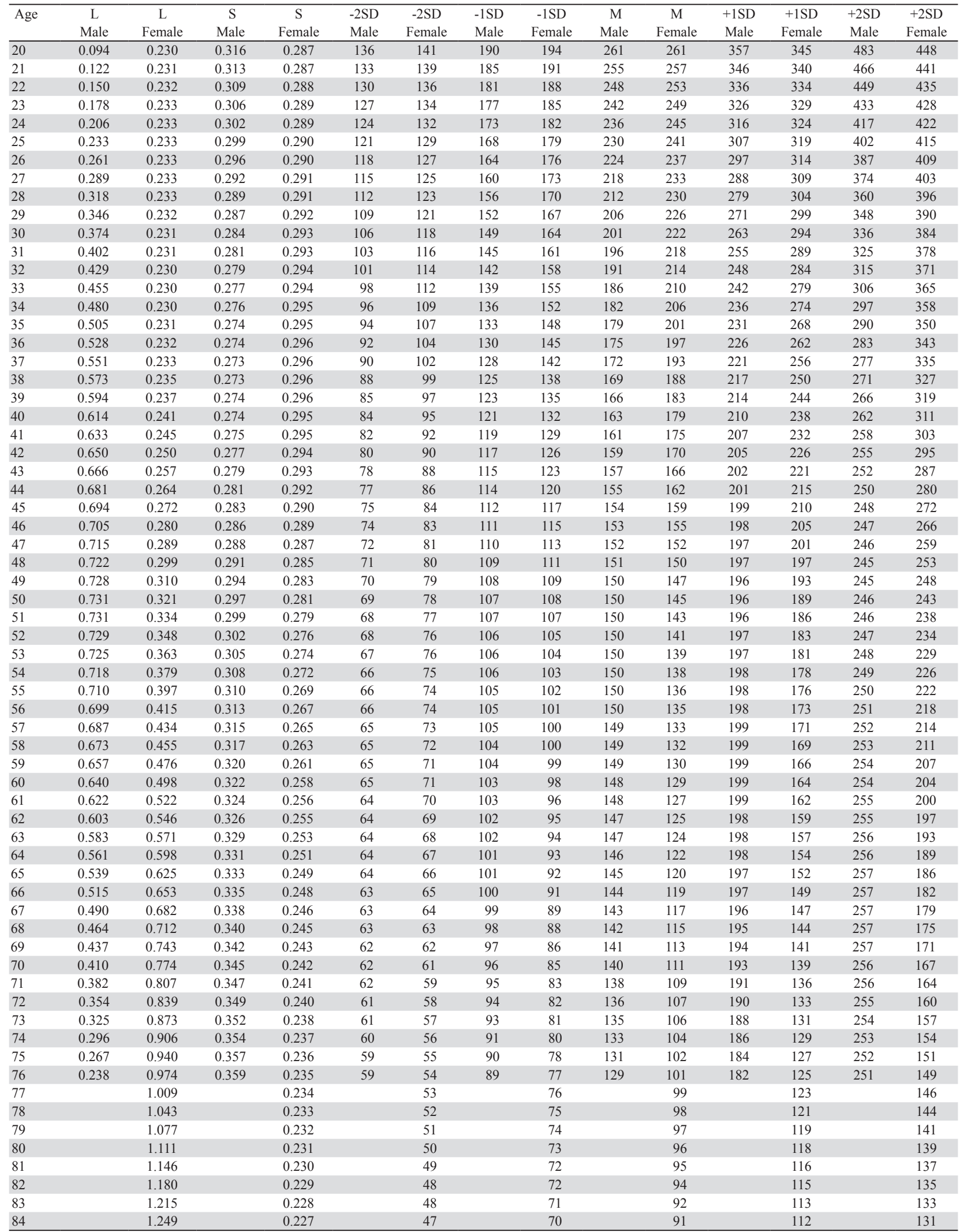

L, Coefficient of skewness; S, Coefficient of variation; M, Median. 


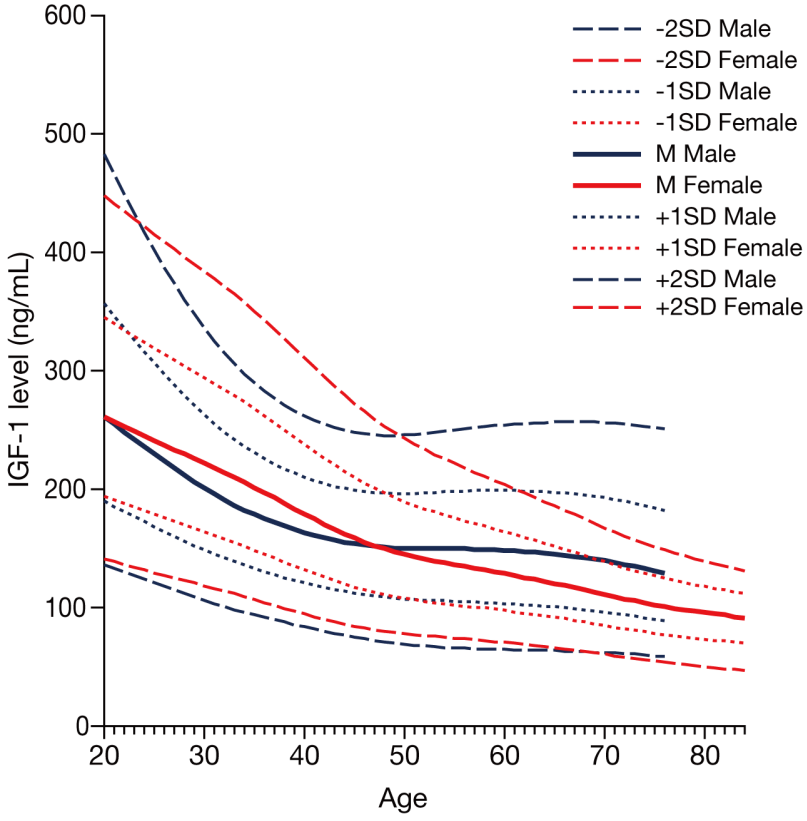

Fig. 1 Centile curves of IGF-1 vs age using the LMS method (aged 20-84)

As we know, a variety of factors, such as age, gender, race, level of nutrition, disease (diabetes, infection diseases, obesity, cancer et al.), and detection methods, could affect IGF-1 levels [11]. When we study elder people, it is not very easy to have perfectly healthy candidates without any abnormal conditions. Here the volunteers were perfectly healthy, aged 20 to 84 years old, with equal five year intervals. An inverse U-shaped association of IGF-I SDS with BMI, waist circumference. The IGF-1 decreased when BMI was more than $32.5 \mathrm{~kg} / \mathrm{m}^{2}$ [12]. Here, the BMI of the volunteers were between $18.5-28 \mathrm{~kg} / \mathrm{m}^{2}$.

Age is the most important factor contributing to IGF-1 variation. An Italian report [13] studied the inpatient and outpatient children aged 0 to 18 and the peak IGF-1 was 15 years old, which was in accordance with the Elmlinger's data [5]. Alice P.S. Kong established the reference values of IGF-1 in Chinese adolescents aged 12-19 years, the transition period, although not analysis in its correlation with pubertal stages. They reported that IGF-1 tended to be higher in girls than boys before the age of 16. In boys, the peak was at the ages of 13-14. In girls, there was a similar decline after the age of 12 [14]. Here, the age- and gender-specific normal ranges were established for Chinese adults over 20 years old using the LMS method. The Z-score of serum IGF-I measurement (y value) was calculated from the L, M and S curves, using values appropriate for the age and gender, by the following equation: $Z=\left[(y / M)^{L}-1\right] /(L \times S)$, and if $\mathrm{L}=0, \mathrm{Z}=\log (\mathrm{y} / \mathrm{M}) / \mathrm{S}$ [9]. The $\mathrm{Z}$-score of IGF-1 is an ideal, precise and standardized index in evaluation of the function of GH-IGF-1 axis $[8,9]$. The $\mathrm{Z}$ scores have not been widely accepted in IGF-1 evaluation nowadays, only a rough statement of higher/ lower than the normal range [1]. We appealed the utilizing of $\mathrm{Z}$ scores, rather than the roughly classified terminology 'higher/lower than normal', because it is a standardized score and achievable in digitalized statistic analysis. A Z score is a parameter after race, gender, age or lab calibrations.

It is controversial and inconsistent about the influence of gender on IGF-1 levels $[15,16]$. This study showed that there was significant difference between males and females in some subgroups of age. Middle-aged females had higher and elder females had lower IGF-1 than males. These results of Table 1 and Fig. 1 showed that the gender difference varied depending on the age. The reason might be because of the sex hormones [16]. Some experts suggested that a common adult serum IGF-1 reference range seems to be reasonable for clinical practice because the gender difference is small [16]. However, with a computer application program, it is easy to calculate a Z-score for a male/female at a certain age. The IGF-1 Z-score of an individual provided a more precious index. It's unreasonable to neglect the slight gender difference.

We want to know if there is a difference of IGF-1 between this cohort and Elmlinger's [5]. Here, we are capable of comparing the Mean values between the two cohorts at each comparative subgroups of age without BMI adjustment, although the comparison power by the Summary $t$-test of Means is not high in general. The difference of IGF-1 levels between this study and Elmlinger existed in three sub-groups, showing a slight racial difference between China and Germany. This result supported the importance of an ethnic specific reference range for a precise investigation [2].

The limitation of this study is the lack of healthy volunteers under the age of 20 . The present study established age- and gender-specific normal ranges of IGF-I for the Chinese adults. The gender/race differences varied depending on the age. We appealed the application of IGF-1 Z score for the research precision purpose or in clinical practice. 


\section{Acknowledgment}

Thanks to all the healthy volunteers who participated. The authors also thank Wanping Deng and other nurses who contributed to the volunteer's enrollments, taking blood samples and laboratory work.

\section{Disclosure}

This research was supported by Beijing Novartis Pharma Co. Ltd [Original 2013(2618)-OBU (505)$10(272)]$. None of the authors have any potential conflicts of interest associated with this research.

\section{References}

1. Katznelson L, Laws ER Jr, Melmed S, Molitch ME, Murad MH, et al. (2014) Acromegaly: an endocrine society clinical practice guideline. J Clin Endocrinol Metab 99: 3933-3951.

2. Berrigan D, Potischman N, Dodd KW, Hursting SD, Lavigne J, et al. (2009) Race/ethnic variation in serum levels of IGF-I and IGFBP-3 in US adults. Growth Horm IGF Res 19: 146-155.

3. Giustina A, Barkan A, Casanueva FF, Cavagnini F, Frohman L, et al. (2000) Criteria for cure of acromegaly: a consensus statement. J Clin Endocrinol Metab 85: 526-529.

4. Aimaretti G, Boschetti M, Corneli G, Gasco V, Valle D, et al. (2008) Normal age-dependent values of serum insulin growth factor-I: Results from a healthy Italian population. J Endocrinol Invest 31: 445-449.

5. Elmlinger MW, Kuhnel W, Weber MM, Ranke MB (2004) Reference ranges for two automated chemiluminescent assays for serum insulin-like growth factor I (IGF-I) and IGF-binding protein 3 (IGFBP-3). Clin Chem Lab Med 42: 654-664.

6. Plengpanich W, Mangkala J, Buranasukajorn P, Boonruang K, Sunthornyothin S, et al. (2008) Normal Reference Range of Serum Insulin-Like Growth Factor (IGF)-I in Healthy Thai Adults. J Med Assoc Thai 91: 1681-1684.

7. Rosario PW (2010) Normal values of serum IGF-1 in adults: results from a Brazilian population. Arq Bras Endocrinol Metabol 54: 477-481.

8. Isojima T, Shimatsu A, Yokoya S, Chihara K, Tanaka T, et al. (2012) Standardized centile curves and reference intervals of serum insulin-like growth factor-I (IGF-I) levels in a normal Japanese population using the LMS method. Endocr J 59: 771-780.
9. Cole TJ, Green PJ (1992) Smoothing reference centile curves: the LMS method and penalized likelihood. Stat Med 11: 1305-1319.

10. Mukherjee A, Shalet SM (2010) The value of IGF1 estimation in adults with GH deficiency. Eur J Endocrinol 161: S33-S39.

11. Brabant G, Wallaschofski H (2007) Normal levels of serum IGF-I: determinants and validity of current reference ranges. Pituitary 10: 129-133.

12. Schneider HJ, Saller B, Klotsche J, Marz W, Erwa W, et al. (2006) Opposite associations of age-dependent insulin-like growth factor-I standard deviation scores with nutritional state in normal weight and obese subjects. Eur J Endocrinol 154: 699-706.

13. Bedogni G, Giannone G, Maghnie M, Giacomozzi C, Di Iorgi N, et al. (2012) Serum insulin-like growth factor-I (IGF-I) reference ranges for chemiluminescence assay in childhood and adolescence. Data from a population of in- and out-patients. Growth Horm IGF Res 22: 134-138.

14. Kong AP, Wong GW, Choi $\mathrm{KC}$, Ho CS, Chan MH, et al. (2007) Reference values for serum levels of insulinlike growth factor (IGF-1) and IGF-binding protein 3 (IGFBP-3) and their ratio in Chinese adolescents. Clin Biochem 40: 1093-1099.

15. Tiryakioglu Ö, Kadiolgu P, Canerolgu NÜ, Hatemi $\mathrm{H}$ (2003) Age dependency of serum insulin like growth factor (IGF)-1 in healthy Turkish adolescents and adults. Indian J Med Sci 57: 543-548.

16. Brabant $\mathrm{G}$, von zur Mühlen A, Wüster C, Ranke MB, Kratzsch J, et al. (2003) Serum Insulin-Like Growth Factor I Reference Values for an Automated Chemiluminescence Immunoassay System: Results from a Multicenter Study. Horm Res 60: 53-60. 